\title{
Structural serviceability under impact and dynamic loading
}

\author{
A. Farah \\ School of Engineering, Laurentian University, Canada
}

\begin{abstract}
The behavior of structures relative to the comfort of the human user is an important factor in the design process. A tall building is designed to withstand specified seismic and wind loads, and to remain safe from collapse or life-threatening damage under the maximum load, and to undergo no structural damage or user discomfort when the building is subjected to minor earthquakes or wind actions. Similarly, floors subject to human activity such as walking, jumping, running and dancing should be designed such that the resulting vibrations are not annoying or disturbing to the human occupants. The serviceability of such structures is dependent upon the imposed excitation and the characteristics of the structure such as frequency, mass, stiffness and damping. Thus, in order to ensure that a structure is serviceable, it is desirable to use a serviceability criterion that is based on human response to vibration during the interaction of the human and the vibrating structure. In this paper, the serviceability of floors and tall buildings is assessed in terms of the absorbed power (rate of energy dissipation) through biomechanical models of the human in the vertical and fore-and-aft (horizontal) modes respectively. This quantity has been shown to be a reliable indicator of human response to vibration. The forcing function on tall buildings is estimated from statistical data of past earthquakes or wind actions as represented by the relevant power spectra for the location, and that acting on floors by heel impact and the forcing function during walking or dancing. The results indicate that in the case of tall buildings, absorbed power discerns comfort levels at different floor levels, and in the case of floors, that absorbed power is a good predictor of floor serviceability. Serviceability design curves are presented to enable the designer to arrive at serviceable designs.
\end{abstract}

Keywords: tall buildings, floors, serviceability, human comfort, biomechanical models, seismic loads, wind loads, absorbed power, floor design curves, tall building design curves. 


\section{Introduction}

Long-span structures such as floors and tall buildings, built with materials possessing low damping, are likely to exhibit perceptible or annoying vibrations under dynamic loading although the relevant building code requirements for strength and deflection are met. The serviceability of a structure to vibration is dependent upon the imposed excitation and the characteristics of the structure such as frequency, stiffness, mass and damping. Additionally, since the human user is the recipient of the vibrations, then any objective criterion for assessing structural serviceability should incorporate the characteristics of the human user. Several serviceability criteria such as displacement, velocity and acceleration have been proposed by researchers, Chen and Robertson [1], Chang [2], Goldman and Von Gierke [3], Lenzen and Murray [4], and Allen [5]. Such criteria, coupled with frequency, specify the maximum allowable response of the structure that avoids disagreeable vibrations relative to the human user. To avoid the use of several criteria that sometimes are in conflict with each other, an objective criterion based on absorbed power (rate of energy dissipation) through the human body as represented by a biomechanical model has been developed by Farah [6]. This criterion has been shown to be a good measure of the serviceability of tall buildings and floors Farah [7].

\section{Absorbed power}

Absorbed power is a measure of human comfort relative to vibration. The higher the value of absorbed power, the higher the discomfort level will be. Absorbed power for steady state vibrations is defined as:

$$
P=\lim _{T \rightarrow \infty} \frac{1}{T} \int_{0}^{T} f(t) v(t) d t
$$

where $f(t)$ and $v(t)$ refer respectively to the force and velocity at the point of contact between the human as represented by a biomechanical model, and the floor, and $\mathrm{T}$ is the period of time. Note that for transient vibrations, the power should be averaged over a finite period of time. A three second period would be adequate for the human to react to the vibration. The expression for absorbed power in the frequency domain is obtained by using Fourier transforms:

$$
P=-\frac{1}{\pi} \int_{0}^{\infty} \omega P_{y}(\omega) \operatorname{Im} G(\omega) d \omega
$$

where $\omega$ is the circular frequency, $\mathrm{P}_{\mathrm{y}}(\omega)$ is the power spectrum of the displacement and $G(\omega)$ is the transfer function between the force and displacement at the point of contact, and Im refers to the imaginary component. 


\section{Biomechanical models}

To simulate human response to vertical and horizontal vibrations, biomechanical models were developed for this purpose. A two-degrees-of-freedom model for vertical vibrations, fig. 1 and a three-degrees-of-freedom model for horizontal (fore and aft) vibrations, fig. 2 were developed, Farah [6]. The parameters of the models were obtained by fitting available frequency response or impedance data to the corresponding quantities of the biomechanical models.

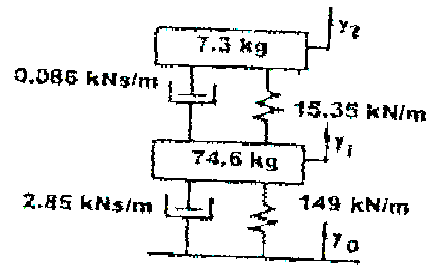

Figure 1: Two-degree model of Figure 2: standing man.

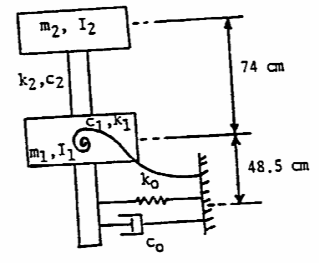

Three-degree model of standing man in the fore and aft mode.

\section{Serviceability of tall buildings}

A tall building is designed to be functional and meet the design criteria for structural integrity as well as be serviceable relative to the human occupant. Building serviceability has been studied by many researchers who produced relevant recommendations, $[1,2]$. It is generally accepted that accelerations of the order of $0.5-1 \% \mathrm{~g}$ are perceptible, $1-5 \% \mathrm{~g}$ are annoying, and $>15 \% \mathrm{~g}$ are disturbing. Chang [2] produced human comfort curves for occupants of buildings that are a function of the magnitude and frequency of vibration. However, Farah [7] showed that these curves correspond to constant levels of absorbed power. Based on these curves, the thresholds of perception and annoyance correspond to absorbed power levels of $1.33 \times 10^{-4}$ and $8.00 \times 10^{-4}$, fig. 3. Examples of buildings subjected to wind action, and seismic loading are given below.

\subsection{Building subjected to wind action}

The absorbed power is calculated by considering the response of the biomechanical model due to the motion of the building at the feet of the human. In turn, the building motion spectrum in the frequency domain is obtained as the product of the wind force spectrum and the mechanical admittance of the building. The building motion spectrum is then substituted into eqn. (2) to obtain the absorbed power. Note that the wind force spectrum is a function of the wind velocity, the wind density, and the drag coefficient. The mean wind velocity can be represented by the power law as: 


$$
v(z)=v_{z 0}\left(z / z_{0}\right)^{\alpha}
$$

where $\mathrm{v}(\mathrm{z})$ is the wind velocity at height $\mathrm{z}, \mathrm{z}_{0}$ is a reference height $(10 \mathrm{~m}), \mathrm{v}_{\mathrm{z} 0}$ is the velocity at the reference height and $\alpha$ is a parameter varying from 0.16 in an open terrain to 0.4 in the center of a large city. The wind force spectrum is given by:

$$
S_{F}=\chi_{F V} S_{V}
$$

where $\mathrm{S}_{\mathrm{F}}$ and $\mathrm{S}_{\mathrm{V}}$ are the power spectra of the wind force and the wind velocity respectively, and $\chi_{F V}$ is the aerodynamic admittance and is equal to $\left(\rho \mathrm{C}_{\mathrm{w}} \mathrm{A} \mathrm{v} \mathrm{v}^{2}\right)$. $\rho$ is the air density, $C_{w}$ is drag coefficient, $A$ is projected area, and $v$ is the mean velocity.

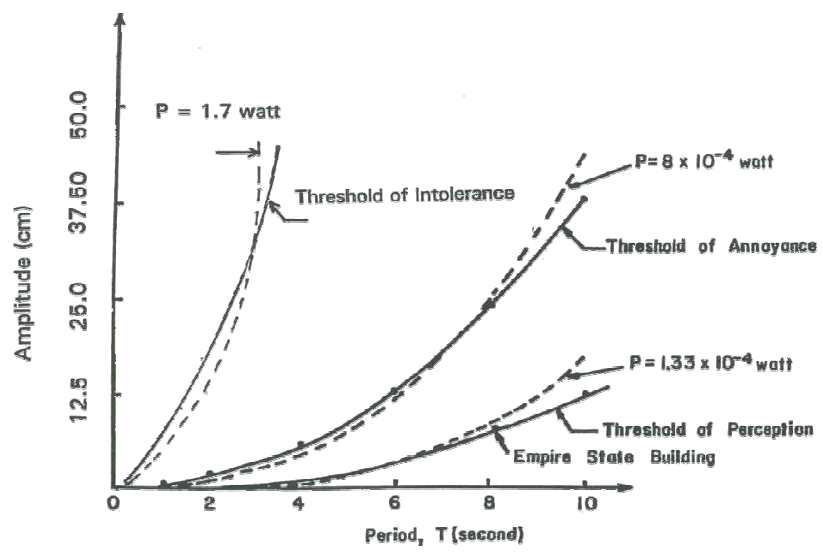

Figure 3: Vibration for thresholds for buildings.

As an example, the absorbed power is calculated for a building when located in an open terrain and when in the center of a large city. The building has a width of $70 \mathrm{~m}$, a height of $400 \mathrm{~m}$, a depth of $50 \mathrm{~m}$, and a frequency of $0.125 \mathrm{~Hz}$. The reference velocity at $10 \mathrm{~m}$ is taken as $17.5 \mathrm{~m} / \mathrm{s}$.

The results are shown in figs. 4 and 5. Fig. 4 shows that damping of the order of $1.6 \%$ of critical would be needed to render the vibrations imperceptible when the building is in open terrain. The corresponding value for the building in the center of a large city is $25 \%$ of critical which is extremely difficult to attain.

\subsection{Building subjected to seismic excitation}

Another example is the response of an eight story building in an earthquake zone. The building is subjected to an acceleration power spectrum based on the 1985 Mexico earthquake. Figs. 6 shows that at a shear velocity of $400 \mathrm{~m} / \mathrm{s}$, high 
absorbed power values of the order of $3.75 \mathrm{~W}$ were calculated placing this vibration above the threshold of intolerance.

This reflects the major damage caused by the earthquake. The severe response is due to the quasi resonant condition that was setup due to the near coincidence of the frequencies of the soil-structure system, the biomechanical model and the earthquake power spectrum.

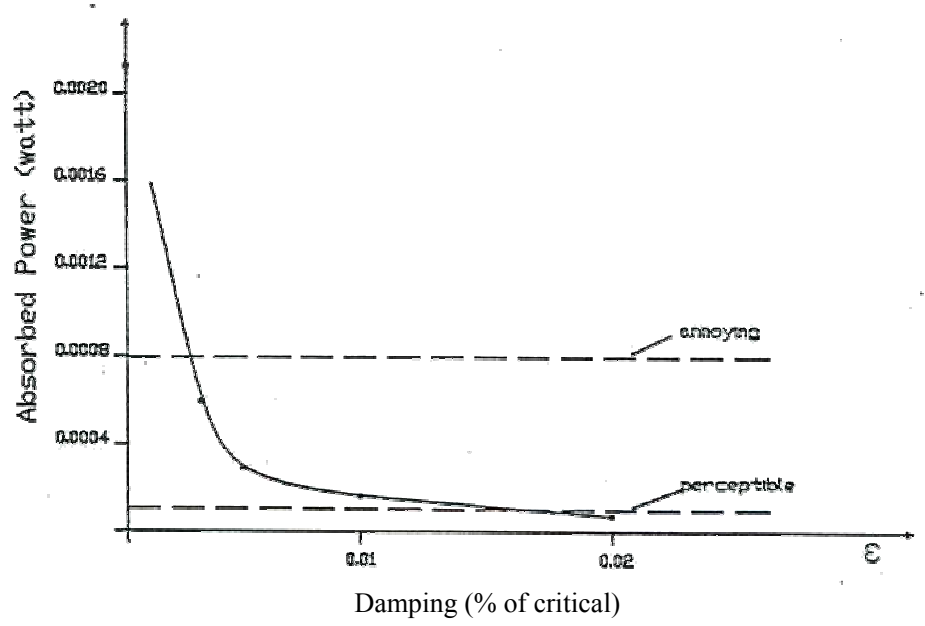

Figure 4: Serviceability of tall building in an open terrain.

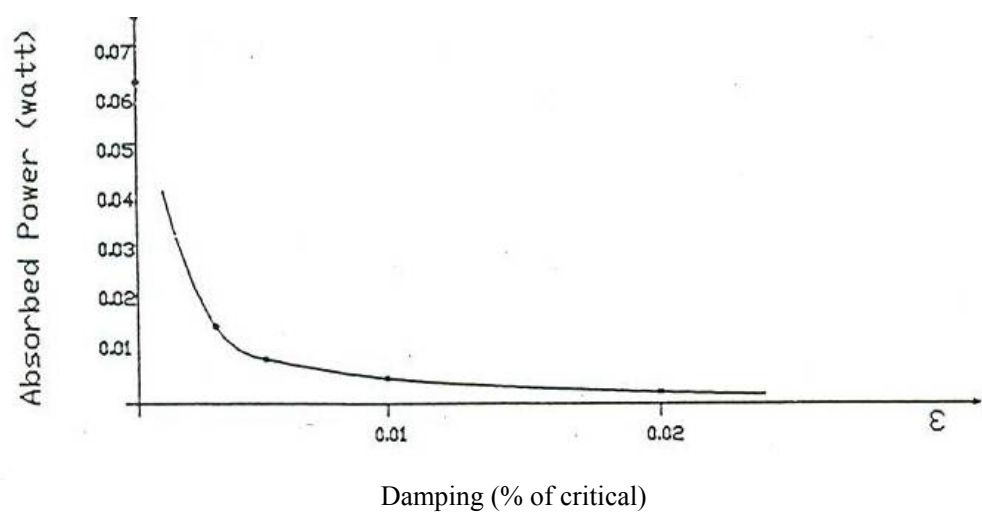

Figure 5: Serviceability of tall building in a center of large city.

\section{Floor subjected to human activity}

Floors can be subjected to human activity such as walking, jumping, dancing, etc. The vibration that results from such activity can impair the serviceability of the floor relative to the human occupant, and in the case of vigorous dancing 
resonance may be setup and damage to the floor could occur. Additionally, serviceability problems can arise due to transient vibrations.

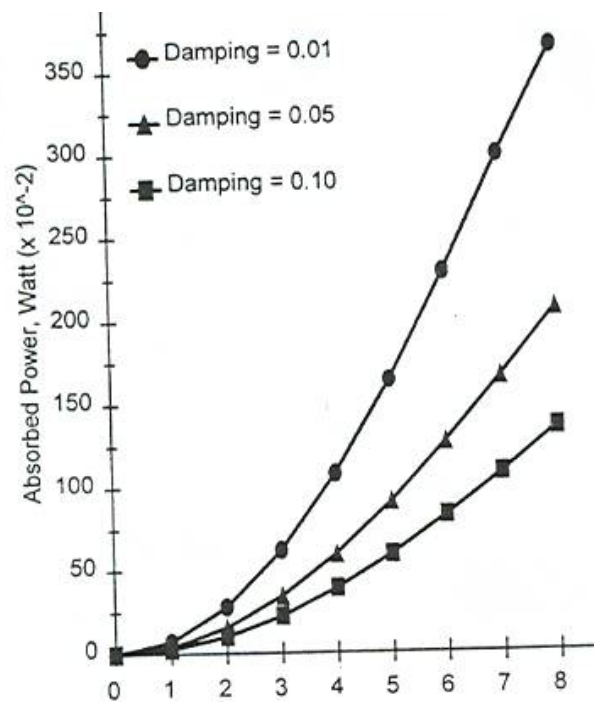

Figure 6: Effect of damping ratio in structure on absorbed power (shear velocity $=400 \mathrm{~m} / \mathrm{s}$ ).

\subsection{Floor subjected to walking and heel impact}

Depending on the type of construction, a floor can be analyzed as a one-way or a two-way slab or as a plate. As an example, consider a floor modeled as a beam, having a span of $10.6 \mathrm{~m}$, an equivalent mass of $1,000 \mathrm{~kg} / \mathrm{m}$, and $8 \%$ of critical damping. The floor was subjected to a human of mass $72 \mathrm{~kg}$ walking with a heel impact of $667 \mathrm{~N} . \mathrm{s}$ at $2 \mathrm{steps} / \mathrm{s}$ and a step length of $0.75 \mathrm{~m}$. The absorbed power by a human (represented by a biomechanical model) standing at mid-span is shown in fig. 7.

It is seen that there are four quasi-resonances; two of these are near 2 and $6.6 \mathrm{~Hz}$, and the other two are near 4 and $11 \mathrm{~Hz}$. The 6.6 and $11.0 \mathrm{~Hz}$ frequencies are associated with the first two resonant frequencies of whole body vibration, while the 2 and $4 \mathrm{~Hz}$ frequencies are multiples of the cadence of walking. It is observed that the maximum absorbed power is $0.0052 \mathrm{~W}$ which place the vibrations in the perceptible-annoying range.

\subsection{Floor subjected to transient vibration}

The serviceability of floors under transient loading is approximated by the absorbed power resulting from a standard heel drop test that acts over a period of $50 \mathrm{~ms}$ and has an impulse of $66 \mathrm{~N} . \mathrm{s}$. Using an absorbed power of $0.0035 \mathrm{Watt}$, that ensures that a floor is serviceable, design curves relating frequency and critical damping for various masses were produced. 


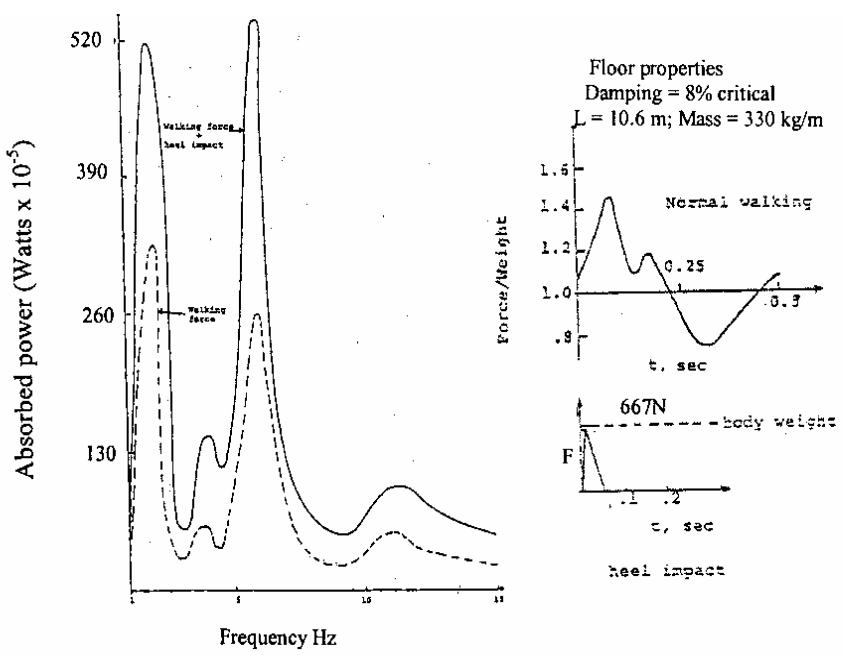

Figure 7: Floor resonance due to normal walking and heel impact ( 2 steps/s, step length $=0.45 \mathrm{~m})$.

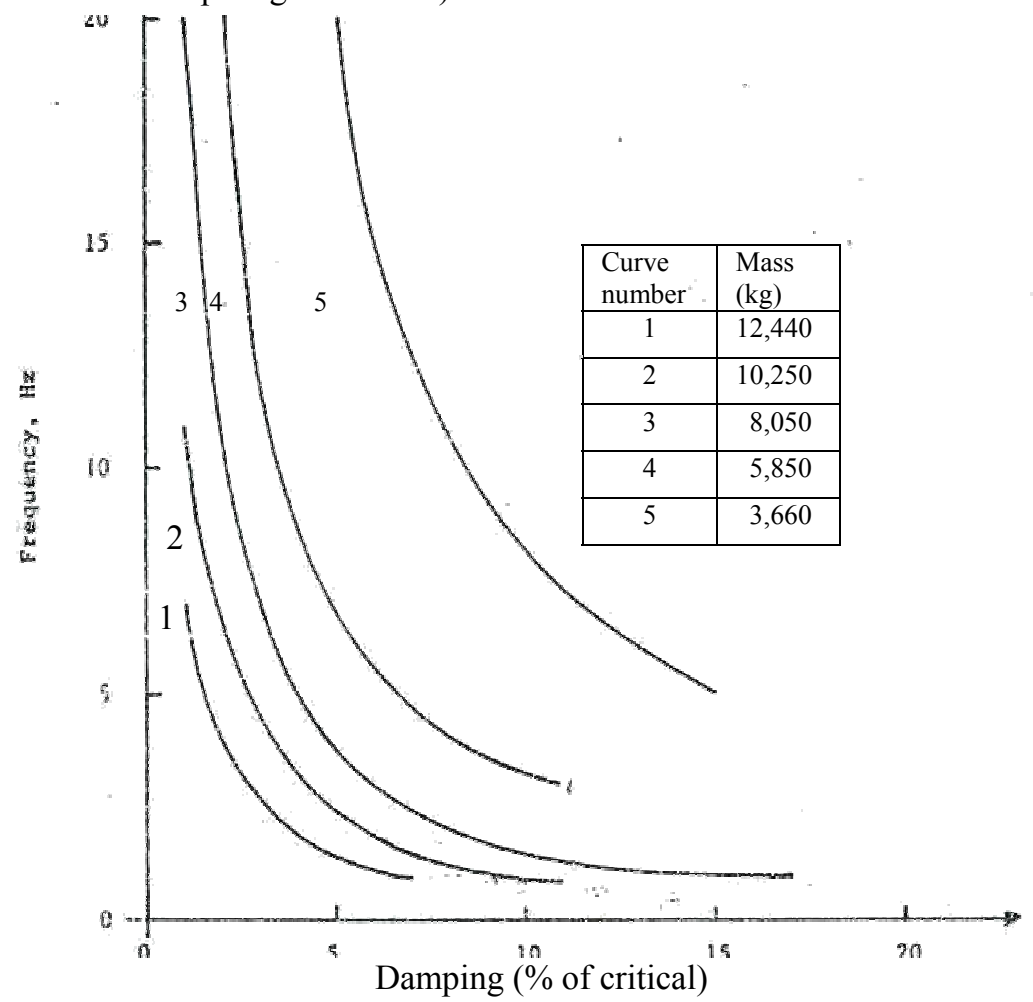

Figure 8: Variation of frequency and damping for serviceable floor design (various equivalent floor masses). 
For example, a floor with a fundamental frequency of $10 \mathrm{~Hz}$ and an equivalent mass of $5,850 \mathrm{~kg}$ would require a minimum of $3.5 \%$ of critical damping to meet the serviceability requirement.

\section{References}

[1] Chen, R.W. \& Robertson, L.E., Human perception thresholds of horizontal motion, J. Struct. Div. ASCE, ST8, pp. 1681-1695, 1972.

[2] Chang, F.K., Human response to motion in tall buildings, J. Struct. Div., ASCE, ST8, pp. 1259-1272, 1973.

[3] Goldman, D.E. \& Von Gierke, H.E, Effects of Shock and vibration on man (Chapter 44), Shock and Vibration Handbook, McGraw Hill, New York, 1961.

[4] Lenzen, K.H. \& Murray, T.M., Vibration of steel beam-concrete slab floor systems, Studies in Engineering Mechanics, Report no. 29, The University of Kansas, Lawrence, Kansas, 1970.

[5] Allen, D.E., Vibrational behaviour of long-span floor slabs, Canadian Journal of Civil Engineering, 1(1), Sep. 1974.

[6] Farah, A., Human Response: A Criterion for the Assessment of Structural Serviceability, Ph.D. Thesis, University of Waterloo, Waterloo, Canada, pp.19-32, 1977.

[7] Farah, A., Structural serviceability under dynamic loading, Special Publications SP-86-19, The American Concrete Institute, Detroit, pp. 41934, 1986. 